\title{
Performance of $\mathrm{CuS}$ nanoparticle loaded on activated carbon in the adsorption of methylene blue and bromophenol blue dyes in binary aqueous solutions: Using ultrasound power and optimization by central composite design
}

\author{
Hamed Mazaheri ${ }^{\text {a }}$, Mehrorang Ghaedi ${ }^{* a}$, Arash Asfaram ${ }^{\text {a }}$, Shaaker Hajati ${ }^{\mathrm{b}}$ \\ ${ }^{a}$ Department of Chemistry, Yasouj University, Yasouj 75918-74831, Iran \\ ${ }^{b}$ Department of Physics, Yasouj University, Yasouj 75918-74831, Iran
}

\begin{abstract}
In this research, simultaneous adsorption of Bromophenol blue (BPB) and Methylene blue (MB) dyes in binary mixture onto activated carbon modified with $\mathrm{CuS}$ nanoparticle were studied. The $\mathrm{CuS}$ nanoparticle loaded on activated carbon (CuS-NP-AC) was synthesized and identifying by SEM and XRD analysis. The effect of $\mathrm{pH}$ on their removal percentage in single and binary system were examined, while the individual and combination effect of factors variables such as concentration of MB and BPB, amount of adsorbent and sonication time were studied by central composite design (CCD). Then, the adsorption kinetics and their isotherms investigation in binary solution reveal that data well fitted by Langmuir model in comparison to other models with maximum mono layer loading capacities of 106.4 and $208.3 \mathrm{mg} \mathrm{g}^{-1}$ of adsorbent for BPB and $\mathrm{MB}$ respectively in single-component. Ultrasonic is used instead of conventional magnetic stirrer to accelerate mass transfer and simultaneously shortened the removal time and amount of adsorbent. Sonication by lateral bubbling cause enhance in diffusion coefficient and finally enhance the removal percentage.
\end{abstract}

Keywords: Adsorption, Central composite design, CuS-NP-AC, Isotherm and Kinetics Studies, Ultrasound.

\section{Introduction}

Dyes, pigments and heavy metal ion as common and dangerous pollutants enter to various ecosystems through textile pulp, leather, paper and plastics industries which subsequently cause generation of harmful hazards and problem for environment. Contaminants like color [1, 2]. Appearance causes generation of

\footnotetext{
* Corresponding author at: Tel.: +98 741 2223048; fax: +98 7412223048.

E-mail address: m_ghaedi@mail.yu.ac.ir; m_ghaedi@yahoo.com (M. Ghaedi)
} 
various hazards such as mutagen and carcinogenic problem for living organism and because of strong inhibition of oxygen penetration to the water media reduce photosynthesis. [3].

Bromophenol blue (Fig. 1a) as triphenylmethane derivatives in addition to fluoresceins and xanthenes are widely used for foods, drugs, cosmetics, textiles, printing inks or laboratory indicators $[4,5]$. Methylene blue (Fig. 1b) with remarkable and extensive application for dying cotton, wood and silk cause lateral eye burns which may be responsible for permanent injury to the eyes of human and animals. Short period's inhalation while ingestion through the mouth produces a burning sensation and problem like nausea, vomiting, profuse sweating and mental confusion [6-8]. Therefore, the treatment of effluent containing such dye has great interest to limit lateral their impacts.

Importance of wastewater quality $[9,10]$ is associated with application of various physical and chemical methods such as coagulation [11], reverse osmosis [12], photo-degradation [13], electrochemical oxidation [14], ozonation [15], biosorption [16, 17] and adsorption [7, 18-20] to achieve clean ecosystem.

The majority of researchers concern to removal of heavy metals and dyes correspond to multi-component systems analysis is belong to that investigation of competitive pollutants adsorption which encourage researchers to develop efficient water purification processes [21-23]. Presence of more number of pollutants in solution strongly affect the adsorption capacity of the adsorbent $[22,24]$ so that its performance depend on the number of pollutants present in solution and their concentration. To date, the amount of literature on adsorption processes for simultaneous dye and heavy metal ions removal from water in multicomponent systems is rather limited [4, 22, 25-27].

Adsorption especially based on unique remarks like simple design, easy operation based on application of green and non-toxic adsorbent is good candidate for removal of huge amount of dyes in short time using at least reagent consumption [10,28-30]. Deposition and loading nanoparticles onto activated carbon as most conventional and popular material lead to increase in reactive center and adsorption capacity. Nanoparticles possess distinguished properties such as high number of reactive atoms and large number of vacant reactive metallic or semi-metallic centers are applicable for accumulation for various functional and reactive groups (atoms) [31-34]. The CuS-NP-AC was synthesized and subsequent characterized by SEM and XRD analysis and subsequently were used for quantitative and sorption of high quantity of MB and BPB from multi-solution in short time.

Sonication cause more acceleration of removal percentage over short time using small amount of adsorbent [35]. Ultrasound via secondary activity like cavitation (nucleation, growth and transient collapse of tiny gas bubbles) improve the mass transfer through convection pathway that is emerged from physical phenomena such as micro-streaming, micro-turbulence, acoustic (or shock) waves and micro jets without significant change in equilibrium characteristics of the adsorption/desorption system [36-38]. 
There are many factors affecting the ultrasound-assisted adsorption method such as sonication time, $\mathrm{pH}$, adsorbent dosage and initial dye concentration. A good selection of design and optimization models makes possible to simultaneously evaluate the variables contribution (main and interaction) on adsorption process which in present study was obtained by experimental design [29, 39]. Response surface methodology (RSM) is enables the researchers to get optimum condition using the first or second order polynomial equations. In this work, CuS-NP-AC was used for the simultaneous removal of MB and BPB dyes from synthetic solution in the presence of ultrasound. The result was evaluated by analysis of variance (ANOVA). The model was validated and plotted in response profile. A surface response that corresponds to a response function was used to determine the best operating condition of the process.

\section{Experimental}

\subsection{Reagents and Instruments}

The stock solution (500 $\mathrm{mg} \mathrm{L}^{-1}$ ) of MB and BPB were prepared by dissolving appropriate amount of solid dye in double distilled water and respective solution over working daily were prepared following its dilution. All chemicals including $\mathrm{NaOH}, \mathrm{HCl}$ and $\mathrm{KCl}$ with the highest purity available were purchased from Merck (Darmstadt, Germany). The $\mathrm{pH}$ were set by $\mathrm{pH} / \mathrm{Ion}$ meter (Metrohm, model-686, Switzerland, Swiss) and the MB and BPB quantification were determined using UV-Vis spectrophotometer (JASCO, model V-530, Japan) at 664 and $590 \mathrm{~nm}$, respectively. An ultrasonic bath with heating system (TECNOGAZ, Parma, Italy) at $40 \mathrm{kHz}$ of frequency and $130 \mathrm{~W}$ of power was used for the ultrasound-assisted adsorption procedure. X- ray diffraction (XRD, Philips, PW1800, Eindhoven, Netherland) was performed to characterize the phase and structure of the prepared nanoparticles using $\mathrm{cu}_{\mathrm{ka}}$ radiation $(40 \mathrm{KV}$ and 40 $\mathrm{mA}$ ) at angles ranging from 10 to $80^{\circ}$. The BET (Brunauer, Emmett, and Teller) surface areas of the adsorbent materials were measured using TriStar II 3020 (Micrometrics Instrument Corporation) surface area analyzer where $\mathrm{N}_{2}$ gas was used as adsorbate. The morphology of the nanoparticles were observed by scanning electron microscopy (SEM: Hitachi S-4160, Tokyo, Japan) under an acceleration voltage of 15 KV.

\subsection{Ultrasound assisted adsorption method}

The removal process was accelerated using ultrasound, while the ultrasonic bath was filled with $2.5 \mathrm{~L}$ water (the sonication medium) at constant temperature during the experiment. The ultrasound assisted adsorption experiment in batch mode was undertaken as follows: specified amounts of mixed dyes solution at different

$\mathrm{pH}$ were mixed with appropriate amount of adsorbent in the presence of ultrasound at room temperature. Finally the sample was immediately centrifuged and the content of non-retained dyes was evaluated based on the calibration curve obtained at the same conditions. The optimum $\mathrm{pH}$ value $(\mathrm{pH}=7.0)$ other effective 
variables including amount of adsorbent, sonication time, $\mathrm{MB}$ and $\mathrm{BPB}$ concentration were optimized with central composite design while their ranges and value was described according to previous studies [4, 25, 40].

\subsection{Measurements of dye uptake}

The dye concentrations were determined at their maximum wavelengths over working concentration (for MB $664 \mathrm{~nm}$ and BPB $590 \mathrm{~nm}$ ). The efficiency of dyes removal was determined at different experimental conditions according to $\mathrm{CCD}$ method. The effect of initial $\mathrm{pH}$ on the $\mathrm{MB}$ and $\mathrm{BPB}$ removal over $\mathrm{pH}$ range of $2.0-8.0$ at $10 \mathrm{mg} \mathrm{L}^{-1}$ of dyes by $0.0091 \mathrm{~g}$ of CuS-NP-AC at $10 \mathrm{~min}$ in single and multi-component was studied. The removal percentage and magnitude of adsorbed of dyes amount $\left(\mathrm{q}_{\mathrm{e}}\left(\mathrm{mg} \mathrm{g}^{-1}\right)\right)$ was calculated according to previous studies $[34,38,41]$ :

Dyes concentrations were calculated as follows in binary system with components of A and B and their content were measured at $\lambda_{1}$ and $\lambda_{2}$ (respectively) to give optical densities of $d_{1}$ and $d_{2}$ :

$$
\begin{gathered}
\mathrm{C}_{\mathrm{A}}=\left(\mathrm{k}_{\mathrm{B} 2} \mathrm{~d}_{1}-\mathrm{k}_{\mathrm{B} 1} \mathrm{~d}_{2}\right) /\left(\mathrm{k}_{\mathrm{A} 1} \mathrm{kB}_{2}-\mathrm{k}_{\mathrm{A} 2} \mathrm{k}_{\mathrm{B} 1}\right) \\
\left.\mathrm{C}_{\mathrm{B}}=\left(\mathrm{k}_{\mathrm{A} 1} \mathrm{~d}_{2}-\mathrm{k}_{\mathrm{A} 2} \mathrm{~d}_{1}\right) / \mathrm{k}_{\mathrm{A} 1} \mathrm{k}_{\mathrm{B} 2}-\mathrm{k}_{\mathrm{A} 2} \mathrm{k}_{\mathrm{B} 1}\right)
\end{gathered}
$$

where $\mathrm{k}_{\mathrm{A} 1}, \mathrm{k}_{\mathrm{B} 1}, \mathrm{k}_{\mathrm{A} 2}$ and $\mathrm{k}_{\mathrm{B} 2}$ are the calibration constants for components $\mathrm{A}$ and $\mathrm{B}$ at $\lambda_{1}$ and $\lambda_{2}$, respectively. After experiments, the samples were centrifuged at $5000 \mathrm{rpm}$ and MB or BPB dyes concentration was determined.

\subsection{Preparation of copper sulfide nanoparticle}

The CuS nanoparticles was prepared according to the following pathway by the reaction of copper acetate $\left(\mathrm{Cu}\left(\mathrm{CH}_{3} \mathrm{COO}\right)_{2}\right)$ with thioacetamide $\left(\mathrm{CH}_{3} \mathrm{CSNH}_{2}\right)$ under nitrogen atmosphere as follow: 0.6, 1.2 and 7.5 mmol of copper acetate, thioacetamide and tri-sodium citrate at $\mathrm{pH}$ of 7.0 was mixed vigorously $(50 \mathrm{~mL})$. Heating the mixture till $40{ }^{\circ} \mathrm{C}(10 \mathrm{~min})$ lead to the growth of citrate-stabilized $\mathrm{CuS}$ nanoparticles and further heating at the same condition for $6 \mathrm{~h}$ because color change to milky white mixed with light yellow. Rapid centrifugation of the mixture is associated with deposition and setting of $\mathrm{CuS}$ nanoparticles and all its impurity was removed by addition of water and ethanol. Finally, the CuS nanoparticles were dried in a vacuum oven for $6 \mathrm{~h}$ prior to being characterized.

\subsection{Design of experiment (DOE)}


The RSM classes including central composite design (CCD), Box-Behnken design and three-level factorial design lead to final constructed mathematical equation which correlate the relation among variables towards their responses [6]. Amongst, $\mathrm{CCD}$ is suitable for fitting quadratic surface with minimum number of experiments and represent numerical value of main and interaction of variables [42].

The CCD consists of a $2^{n}$ factorial runs with $2 n$ axial runs and $n_{c}$ center runs, 16,8 and 7 , respectively was used for investigation of adsorbent mass $\left(X_{1}\right)$, sonication time $\left(X_{2}\right)$, concentration of $\mathrm{MB}\left(\mathrm{X}_{3}\right)$ and $\mathrm{BPB}\left(\mathrm{X}_{4}\right)$ and level of factors in addition to their responses are presented in Table 1. Standard error correspond to center points replication give numerical value of the experimental error and the reproducibility of the data. Empirical model efficiently correlated the response to effective variables using a second-degree polynomial equation [22, 43, 44], while analyzed by STATISTICA (version 10.0).

\section{Result and discussion}

\subsection{Characterization of adsorbent}

The SEM images of the activated carbon surface and the CuS nanoparticle deposited on activated carbon show the homogeneous and relatively smooth surface of the activated carbon (Fig. 2 (a) and (b)). The Xray diffraction patterns of CuS-NPs-AC (Fig. 2 c) are based on three peaks at $2 \theta$ angles of $28^{\circ}, 47^{\circ}$, and $56^{\circ}$ which correspond to the (llll $\left.\begin{array}{lll}1 & 1 & 1\end{array}\right),\left(\begin{array}{lll}2 & 2 & 0\end{array}\right)$ and $\left(\begin{array}{lll}3 & 1 & 1\end{array}\right)$ and confirm crystal planes of cubic lattice structure of copper sulfide nanoparticles. Furthermore, the broad and less sharp diffraction peaks is proportional to small dimensions of copper nanoparticles. Absence of any diffraction peaks related to $\mathrm{CuO}$ or $\mathrm{Cu}(\mathrm{OH})_{2}$ in the XRD pattern confirm its high purity .

\subsection{Effect of $p H$ on adsorption proses}

$\mathrm{pH}$ has more contribution on dyes structure and also strongly affect adsorption efficiency . In general, the uptake efficiency depend on type and magnitude of charge of the adsorbent surface and dye molecule which respective ion exchange mechanism is occurred by releasing exchangeable proton in interlayer and basal plane surfaces. In this study the effect of $\mathrm{pH}$ on the removal of MB and BPB dyes by CuS-NP-AC at various pHs in the both single and binary solution over the range of 2.0-8.0 was investigated (Fig. 3).

Positive correlation among MB removal percentage and $\mathrm{pH}$ is related to point that at lower $\mathrm{pHs}$, abundance of proton lead to apparence of noticeable repulsive force which lateral competition of proton with dyes for surface hinder from their further adsorption. Similar behavior and trend for BPB with lower slope was observed. BPB removal percentage has opposite correlation with $\mathrm{pH}$ and $\mathrm{pH}$ raising lead to decrease in removal percentage. Phenolic groups of BPB has more tendency to positive charge, and at lower pHs more positive charge cause greater amount of BPB adsorption on surface. 
Fig. 3 reveal appearance of maximum removal percentage at $\mathrm{pH}$ of 7.0 in binary solution and both of dyes have similar trend. In the single solute, BPB removal has passive relation with $\mathrm{pH}$ and rice correlation in binary solution was found. In binary solution, both dyes similarly trends to adsorb on adsorbent surface due to interaction between cationic MB and BPB on the adsorbent surface via distinguished attraction. Firstly, MB accumulated on adsorbent and probably in later stage, phenolic and benzene groups of BPB bind to this molecular via different mechanism. In the binary solution, increasing $\mathrm{pH}$ lead to enhancement extension of removal percentage and maximum efficiency was achieved at neutral $\mathrm{pH}(\mathrm{pH}=7.0)$. Optimum $\mathrm{pH}$ for next work was selected at 7.0.

\subsection{Experimental design and optimization}

CCD as most conventional method $[22,30]$ is used for fitting quadratic model that express interaction among parameters and simultaneously represent idea about contribution of each parameter on response with minimum number of experiments (Table 1). The polynomial regression equation for analysis of correlation between variables and responses investigated by was done using CCD give information about individual and synergetic effect of four factors including sonication time, amount of adsorbent, MB and BPB concentration and their removal percentage as responses. The analysis of variance, coefficient of determination $\mathrm{R}^{2}$, the probability p-value (95\% confidence level) and fisher's test were used to evaluate the statistical significance and the characteristics of the reliability of the analysis. Significant terms for both responses with coefficient in polynomial regression equation shown by Eq (3) and (4).

$$
\begin{aligned}
& \mathrm{R} \%_{\mathrm{BPB}}=20.02+8020 \mathrm{X}_{1}+8.6 \mathrm{X}_{2}-1.58 \mathrm{X}_{4}-0.714 \mathrm{X}_{2}^{2}-0.095 \mathrm{X}_{4}^{2} \\
& \mathrm{R} \%_{\mathrm{MB}}=78.8+8362.0 \mathrm{X}_{1}+2.9 \mathrm{X}_{2}-4.8 \mathrm{X}_{3}-0.90 \mathrm{X}_{4}-250.0 \mathrm{X}_{1} \mathrm{X}_{2} \\
& +543.0 \mathrm{X}_{1} \mathrm{X}_{3}+0.32 \mathrm{X}_{2} \mathrm{X}_{3}+0.14 \mathrm{X}_{3} \mathrm{X}_{4}-706722 \mathrm{X}_{1}^{2}-0.23 \mathrm{X}_{2}^{2}-0.20 \mathrm{X}_{3}^{2}
\end{aligned}
$$

In Eqs. $(3,4)$, a negative sign suggests an antagonistic effect, whereas a positive sign indicates a synergistic effect. As shown in Equation $(3,4)$, the amount of adsorbent $\left(\mathrm{X}_{1}\right)$ and sonication time $\left(\mathrm{X}_{2}\right)$ are positive. This indicates that the adsorption of MB and BPB by CuS-NP-AC can be improved when these factors are increased.

The good and successful solving of these equations according to the desirability function (DF) give useful information about applicability of model for predication of simultaneous removal of BPB and MB in aqueous samples with minimum amount of experiments.

The results of the analysis of variance (ANOVA) and regression coefficients of MB and BPB (Table 2) suggest high efficiency of quadratic model $(p<0.050)$ for interpretation of experimental data. The lack of 
fit (LOF) is the variation of the data around the fitted model show the adequacy of model for fitting adsorption data. As shown in Table 2, a p-value of LOF were 0.593 and 0.237 for MB and BPB respectively that suggest high ability of the constructed equation for well presentation and fitting the experimental data. For BHB the terms $\mathrm{X}_{1}, \mathrm{X}_{2}, \mathrm{X}_{2}^{2}, \mathrm{X}_{4}$ and $\mathrm{X}_{4}{ }^{2}$ were found to be significant (means adsorbent amount, sonication time and concentration of BPB affect the removal of BPB in linearly way. In the case of MB $\mathrm{X}_{1}$, $\mathrm{X}_{2}, \mathrm{X}_{3}, \mathrm{X}_{4}, \mathrm{X}_{1}^{2}, \mathrm{X}_{2}^{2}, \mathrm{X}_{3}^{2}, \mathrm{X}_{1} \mathrm{X}_{3}, \mathrm{X}_{2} \mathrm{X}_{3}$ and $\mathrm{X}_{3} \mathrm{X}_{4}$ were significant (i.e. Adsorbent value, sonication time and $\mathrm{MB}$ concentration in linear form, while adsorbent in quadratic and interaction between adsorbent and $\mathrm{MB}$ concentration were significant). Positive and negative coefficients mean the direction of corresponding contribution of terms.

The regression coefficients of the empirical models and the corresponding $\mathrm{R}^{2}$, adjusted $\mathrm{R}^{2}$ values, CV\% and adequate precision are shown in Table 2 . The models fit experimental data reasonably well and all the values of $\mathrm{R}^{2}$ are higher than 0.80 . The "Adequate Precision" show extent of signal to noise ratio and value greater than 4 is desirable [6]. Table 2 shows that for all model equations, the precision ratios indicate adequate signals. Hence these model equations can be used to navigate the design space. The high reliability and precision of the response data were confirmed by values of CV that varied between 1.670 and 3.718 .

Fig. 4 (a, b) suggest presence of acceptable agreement among empirical and predicted response. The results showed that the models can establish optimum adsorption conditions for dyes.

Three dimensional response surfaces for the removal percentage of MB versus significant variables (Fig. 4c) has curvatures in most plot indicate the interaction between the amount of adsorbent and MB concentration. The surface plots show that low adsorbent and high concentration simultaneously lead to lower R\% which is related to the facts that low amount of adsorbent is proportional to lower effective surface areas and strong reduction in dispersion phenomena cause significant removal percentage. The effect of sonication time on the removal percentage of BPB in binary solution (Fig. 4d). Lower sonication time lead to very rapid adsorption due to the high available adsorbent surface area and vacant sites which is much higher in comparison to absence of ultrasound on the other handle, exposure of ultrasound is associated with elevating temperature and lead to enhance in mass transfer emergence from raising diffusion coefficient which enhance in adsorption rate. These figure also show occurrence of more than $95 \%$ of dye removal in the first $6.0 \mathrm{~min}$ and reaching equilibrium after about $7 \mathrm{~min}$ sonication.

The profile for predicted values and desirability option in the STATISTICA software is used for the optimization process. The scale in the range of 0.0 (undesirable) to 1.0 (very desirable) is used to obtain global function (D) which highest value achieved according to efficient selection and optimization of designed variables. The CCD optimization design matrix (Fig. 5) show the maximum removal (99.546 and $96.900 \%$ for $\mathrm{MB}$ and $\mathrm{BPB}$ ) with desirability of 0.985 at conditions set as: $0.0091 \mathrm{~g}$ adsorbent, $7.0 \mathrm{~min}$ sonication time), initial BPB concentration $\left(10.0 \mathrm{mg} \mathrm{L}^{-1}\right)$ and $\mathrm{MB}$ concentration $\left(11.0 \mathrm{mg} \mathrm{L}^{-1}\right)$. The 
reliability of this prediction was examined by conduction of similar experiment at specified optimization conditions. The experimental removal percentages for MB and BPB were 99.340 and $96.140 \%$ with RSD lower than $3.0 \%$ that their evaluation by t-test show non-significant difference with respective value presented by model.

\subsection{Kinetic study of binary system}

Kinetic study of adsorption governs the solute adsorption rate and indicates the adsorption efficiency of the adsorbent and determines its applicability for representation of the experimental data [45]. Insertion of adsorption data to conventional models like pseudo-first and second order, intraparticle diffusion and elovich reveal that rate controlling steps are chemical reaction, diffusion control and mass transport processes.

The pseudo-first order equation is shown by following equation [46]:

$$
\log \left(q_{e}-q_{t}\right)=\log q_{e}-K_{1} t
$$

where $\mathrm{q}_{\mathrm{e}}\left(\mathrm{mg} \mathrm{g}^{-1}\right)$ and $\mathrm{q}_{\mathrm{t}}\left(\mathrm{mg} \mathrm{g}^{-1}\right)$ are the adsorption capacities at equilibrium and at time $\mathrm{t}(\mathrm{min})$, respectively; $\mathrm{K}_{1}$ is the pseudo first- order rate constant $\left(\mathrm{min}^{-1}\right)$. The pseudo-second order rate equation developed by Ho and McKay [47] assumes that the adsorption capacity is commensurate to the number of active sites on the surface. The pseudo-second order equation is defined by:

$$
\frac{\mathrm{t}}{\mathrm{q}_{\mathrm{t}}}=\frac{1}{\mathrm{~K}_{2} \mathrm{q}_{\mathrm{e}}{ }^{2}}+\frac{\mathrm{t}}{\mathrm{q}_{\mathrm{e}}}
$$

where $\mathrm{K}_{2}$ is the pseudo-second order rate constant $\left(\mathrm{g} \cdot \mathrm{mg}^{-1} \cdot \mathrm{min}^{-1}\right)$ and due to rate porous structure of adsorbent the adsorption process may affected by the diffusion process. Hence, to explore the behavior of intraparticle diffusion was fitted by following experimental data [48]:

$$
\mathrm{q}_{\mathrm{t}}=\mathrm{K}_{\mathrm{dif}} \mathrm{t}^{0.5}+\mathrm{C}
$$

where $\mathrm{K}_{\text {dif }}$ is the intraparticle diffusion rate constant $\left(\mathrm{mg} \mathrm{g}^{-1} \mathrm{~min}^{-1 / 2}\right)$.

The linear form of Elovich model equation is generally expressed as [49]:

$$
\mathrm{q}_{\mathrm{t}}=\frac{1}{\beta} \ln (\alpha \beta)+\frac{1}{\beta} \ln (t)
$$


If the adsorption kinetic fits the Elovich model, a plot of $\mathrm{q}_{\mathrm{t}} \mathrm{vs} . \ln (t)$ should yield a linear relationship with a slope of $(1 / \beta)$ and an intercept of $(1 / \beta) \ln (\alpha \beta)$ (Table 3).

The theoretical $\mathrm{q}_{\mathrm{e} \text { (calc) }}$ values correspond to first-order kinetic model did not agree with the experimental values, while it has low correlation coefficients that support its not- suitability for explanation of real data indicated that the pseudo-first order kinetic. Based on this Table, the obtained $\mathrm{R}^{2}$ values for the pseudosecond order kinetic model were higher than 0.990 and the theoretical qe values were very close to the experimental $\mathrm{q}_{\mathrm{e}}$ (exp) values. Thus, the adsorption of MB and BPB on CuS-NP-AC was well described by the pseudo-second order kinetic model. These results indicated that the rate-limiting step in adsorption of $\mathrm{MB}$ and $\mathrm{BPB}$ was chemisorption involving valence forces through the sharing or exchange of electrons between adsorbent and pollutants [50].

The $\mathrm{K}_{2}$ values calculated from the pseudo-second-order kinetic model were higher for MB than for BPB and suggest MB adsorption onto CuS-NP-AC was faster than that of BPB dye. It can be seen that the plot of $\mathrm{q}_{\mathrm{t}}$ versus $\mathrm{t}^{0.5}$ for the adsorption of MB and BPB onto CuS-NP-AC adsorbents were no single line over the whole time range (Figs is not shown) and suggest contribution of more than one mechanism on adsorption. The initial curved stage was attributed to rapid external diffusion and surface adsorption, the second region was the gradual adsorption stage where intraparticle diffusion was the rate limiting step. The third region was the final equilibrium stage where intraparticle diffusion started to slow down due to extremely low pollutant concentration in the solution. Accordingly both surface adsorption and intraparticle diffusion affected MB and BPB adsorption on CuS-NP-AC. The value of $\mathrm{R}^{2}$ for elovich model is low that proof its non-sufficiency for explanation of experimental data. Therefore appropriate to describe the behavior of the system kinetics (Table 3).

\subsection{Equilibrium studies of single and multi-component system}

Adsorption equilibrium isotherm is designed based on mathematical relation of the amount of adsorbed target per gram of adsorbent $\left(\mathrm{q}_{\mathrm{e}}\left(\mathrm{mg} \mathrm{g}^{-1}\right)\right)$ to the equilibrium non-adsorbed amount of dye in solution $\left(\mathrm{C}_{\mathrm{e}}\right.$ $\left.\left(\mathrm{mg} \mathrm{L}^{-1}\right)\right)$ at fixed temperature. Isotherm study is high theoretical and practical interest to obtain knowledge about the surface properties of adsorbent and removal mechanism [51]. Several models have been used in literature to describe the experimental data of adsorption isotherms.

The linear form of Langmuir isotherm model may be written as [52]:

$$
\mathrm{C}_{\mathrm{e}} / \mathrm{q}_{\mathrm{e}}=1 / \mathrm{k}_{\mathrm{L}} \mathrm{q}_{\mathrm{m}}+\mathrm{C}_{\mathrm{e}} / \mathrm{q}_{\mathrm{m}}
$$


where $\mathrm{C}_{\mathrm{e}}, \mathrm{q}_{\mathrm{m}}$ and $\mathrm{K}_{\mathrm{L}}$ are the concentration of adsorbate at equilibrium ( $\mathrm{mg} \mathrm{L}^{-1}$ ), maximum mono layer adsorption capacity $\left(\mathrm{mg} \mathrm{g}^{-1}\right)$ and Langmuir constant $\left(\mathrm{L} \mathrm{mg}^{-1}\right)$, respectively. To study the applicability of the Langmuir isotherm for the equilibrium adsorption linear diagram of $\mathrm{C}_{\mathrm{e}} / \mathrm{q}_{\mathrm{e}}$ against $\mathrm{C}_{\mathrm{e}}$ is plotted. The values of $\mathrm{Q}_{\mathrm{m}}, \mathrm{K}_{\mathrm{L}}, \mathrm{R}_{\mathrm{L}}$ and $\mathrm{R}^{2}$ (correlation coefficient values of all isotherms models) are shown in Table 4. The essential characteristics of the Langmuir isotherm can be expressed by a dimensionless constant called equilibrium parameter $\left(\mathrm{R}_{\mathrm{L}}\right)$ based on following equation: [32, 53]:

$$
R_{L}=\frac{1}{1+K_{L} C_{0}}
$$

where $\mathrm{C}_{0}$ is the initial dye concentration $\left(\mathrm{mg} \mathrm{L}^{-1}\right)$. The nature of the adsorption process to be either unfavorable $\left(R_{L}>1\right)$, linear $\left(R_{L}=1\right)$, favorable $\left(0<R_{L}<1\right)$ or irreversible $\left(R_{L}=0\right)$. Values of $R_{L}$ were indicated that the adsorption processes were favorable. To perform data analysis, the effect of both dye in multicomponent removal performance of CuS-NP-AC has been studied and determined using the $p$-factor. This method is a correlative technique that has been developed and applied to multi component systems [54]. It is an easy-to use method based on a capacity factor $p_{i}$.

$$
p_{i}=\frac{\left(Q_{m, i \text { single-solute }}\right)}{\left(Q_{m, i \text { multi-solute }}\right)}
$$

where $\left(Q_{m, i \text { single-solute }}\right)$ is the maximum monolayer adsorption capacity for pollutant $\mathrm{i}$ in the binary solution and $\left(Q_{m, i}\right.$ milti-solute $)$ is the maximum monolayer adsorption capacity of that pollutant with the same initial concentration in a mono-component solution. (a) $p_{i}>1$ suggest that the adsorption of pollutant $i$ is promoted by the presence of other pollutants, (b) $p_{i}=1$ means no interference from other species on adsorption capacity of pollutant $\mathrm{i}$, and (c) $p_{i}<1$ means the presence of other pollutants suppresses the adsorption of pollutant $i[4,21]$. This analysis has been used to study and characterize the performance of adsorbent in the removal of MB and BPB in binary system. The results reveal that increment of dye concentrations significantly affects their uptake in the binary component system, while significant enhance in respective adsorption capacities for BPB and MB was achieved (i.e., $p_{i}>1.0$ ) in binary solutions. This result indicates each dye has positive influence of adsorption of other dye in binary solution (Table 4).

The Freundlich isotherm model is applicable for non-ideal heterogeneous sorption with the logarithmic decrease in the enthalpy of adsorption with increase in fraction of occupied sites. Freundlich isotherm can be expressed by $[25,55]$ : 


$$
\mathrm{q}_{\mathrm{e}}=\mathrm{K}_{\mathrm{F}} \mathrm{C}^{1 / \mathrm{n}}
$$

where $\mathrm{K}_{\mathrm{F}}$ is adsorption capacity at unit concentration and $1 / \mathrm{n}$ is adsorption intensity. $1 / \mathrm{n}$ values indicate the type of isotherm to be irreversible $(1 / n=0)$, favorable $(0<1 / n<1)$, unfavorable $(1 / n>1)$. Eq. (15) can be modified to a linear form:

$$
\log \mathrm{q}_{\mathrm{e}}=\log \mathrm{K}_{\mathrm{F}}+(1 / \mathrm{n}) \log \mathrm{C}_{\mathrm{e}}
$$

To study the applicability of the Freundlich isotherm for the dye adsorption onto CuS-NP-AC, linear form of $\log \mathrm{q}_{\mathrm{e}}$ versus $\log \mathrm{C}_{\mathrm{e}}$ is plotted. The values of $\mathrm{K}_{\mathrm{F}}, 1 / \mathrm{n}$ and $\mathrm{R}^{2}$ (correlation coefficient) of single and binary system are shown in Table 4.

The linear form of Temkin isotherm is given as:

$$
\mathrm{q}_{\mathrm{e}}=\mathrm{B} \ln \mathrm{K}_{\mathrm{T}}+\mathrm{B} \ln \mathrm{C}_{\mathrm{e}}
$$

where $\mathrm{B}=\mathrm{RT} / \mathrm{b}$ is related to the heat of adsorption, $\mathrm{T}$ is the absolute temperature in Kelvin and $\mathrm{R}(8.314 \mathrm{~J}$ $\mathrm{mol}^{-1} \mathrm{~K}^{-1}$ ) is the universal gas constant [56]. A plot of $\mathrm{q}_{\mathrm{e}}$ versus $\ln \mathrm{C}_{\mathrm{e}}$ enables the determination of the isotherm constants $\mathrm{B}$ and $\mathrm{K}_{\mathrm{T}}$ from the slope and the intercept, respectively. $\mathrm{K}_{\mathrm{T}}$ is the equilibrium binding constant $\left(\mathrm{L} \mathrm{mol}^{-1}\right)$ corresponding to the maximum binding energy and constant $\mathrm{B}$ is related to the heat of adsorption; the values of $\mathrm{K}_{\mathrm{T}}, \mathrm{B}$ and $\mathrm{R}^{2}$ (correlation coefficient) are shown in Table 4.

The Dubinin-Radushkevich (D-R) isotherm model was applied to estimate the porosity, free energy and the characteristics of adsorbents [57, 58]. The D-R isotherm is applicable to homogeneous surfaces. Constant adsorption potential is calculated from the following linear equation.

$$
\ln \mathrm{q}_{\mathrm{e}}=\ln \mathrm{Q}_{\mathrm{s}}-\beta \varepsilon^{2}
$$

where $\beta$ is a constant related to the adsorption energy, $Q_{s}$ is the theoretical saturation capacity and $\varepsilon$ is the Polanyi potential which is generally calculated from Eq. (16).

$$
\varepsilon=\mathrm{RT} \ln (1+1 / \mathrm{Ce})
$$

The slope of the plot of $\ln \mathrm{q}_{\mathrm{e}}$ versus $\varepsilon^{2}$ gives $\beta\left(\mathrm{mol}^{2} \mathrm{~kJ}^{-2}\right)$ and the intercept yields the adsorption capacity, $\left(\mathrm{Q}_{\mathrm{s}}\left(\mathrm{mg} \mathrm{g}^{-1}\right)\right.$. The mean free energy of adsorption (E) which concerns to transport of energy of target molecule to the adsorbent surface which is generally evaluated using the following equation: 


$$
\mathrm{E}=(2 \beta)^{-1 / 2}
$$

The calculated values of D-R parameters in single and binary system are shown in Table 4.

The correlation coefficient values $\left(\mathrm{R}^{2}\right)$ show that the dye removal isotherm using CuS-NP-AC does not follow the Freundlich, Temkin and D-R isotherms (Table 4). The linear fit between the $C_{e} / q_{e}$ versus $C_{e}$ and calculated correlation coefficients $\left(\mathrm{R}^{2}\right)$ for Langmuir isotherm model show that understudy dyes removal isotherm exceptionally follow Langmuir model that suggest especial adsorption of dyes at specific homogeneous sites as mono-layer adsorption onto CuS-NP-AC surface. The $\mathrm{R}_{\mathrm{L}}$ values were also shown the Langmuir model was favorable for adsorption process because all $\mathrm{R}_{\mathrm{L}}$ obtained were less than unity. The values of $\mathrm{E}$ were obtained from D-R model is very useful in predicting the type of adsorption and if the value is less than $8 \mathrm{~kJ} \mathrm{~mol}^{-1}$, then the adsorption is physical in nature and if it is in between $8 \mathrm{~kJ} \mathrm{~mol}^{-1}$ and $16 \mathrm{~kJ} \mathrm{~mol}^{-1}$, then the adsorption is due to exchange of ions [30]. In the present study, the value of $\mathrm{E}$ was found $<8 \mathrm{~kJ} \mathrm{~mol}^{-1}$, so the adsorption was physical in nature [59].

\subsection{Comparison of performance of $C u S-N P$-AC with reported adsorbents}

A comparison of the calculated maximum adsorption capacities $\left(\mathrm{q}_{\mathrm{m}}\right)$ for BPB and MB adsorption from the Langmuir equation and the $\mathrm{q}_{\mathrm{m}}$ values of other adsorbents in the literature are presented in Table 5. As the results show, the present method due to its higher adsorption capacity over short time and usage of small amount of adsorbent is highly recommended and favored waste water treatment. The present method is preferred and superior to the literature in term of satisfactory removal performance for dyes as compared to other reported adsorbents.

\section{Conclusion}

The present work focused the application of $\mathrm{CuS}$ nanoparticle loaded on activated carbon (CuS-NP-AC) as an efficient adsorbent for simultaneous competitive removal of BPB and MB in binary mixture solution. The adsorbent was synthesized and subsequently characterized by SEM, XRD and BET analysis. the adsorption efficiency was dependency on amount of absorbent, sonication time, MB and BPB concentration were efficiently optimized with orthogonal central composite design (CCD) and the results proof good ability of this adsorbent to remove the tested dyes from aqueous solutions. Values of "Prob > F" less than 0.050 indicate model terms have significant effect on biosorption of MB and BPB using adsorbent. The obtained coefficient of variation $\mathrm{R}^{2}$ for $\mathrm{MB}$ was 0.994 , while for $\mathrm{R}^{2}$ it was 0.987 , indicating a high degree of correlation between the responses and the independent variables. The optimal operational conditions of adsorption process were ascertained by CCD modeling and desirability function approach. These optimal 
conditions are: $\mathrm{pH}$ of 7.0, $0.0091 \mathrm{~g} \mathrm{CuS-NP-AC,} 11$ and $10 \mathrm{mg} \mathrm{L}^{-1}$ of MB and BPB and 7 min sonication. The Langmuir adsorption isotherm studies is strongly able to fit and explain experimental data with exceptional and remarkable adsorption capacity of 166.67 for $\mathrm{MB}$, and $91.74 \mathrm{mg} \mathrm{g}^{-1}$ for BPB in binarycomponent and 208.33 for $\mathrm{MB}$, and $106.38 \mathrm{mg} \mathrm{g}^{-1}$ for BPB in single-component. The adsorption rate of $\mathrm{BPB}$ and MB was fast and a pseudo-second-order model fits the experimental data well.

Finally, the prediction capability of the proposed model was verified by additional batch experiments conducted in the experimental scale of the CCD. The validation results clearly confirmed with $95 \%$ certainty that a four factor, five-level CCD experimental design combining with RSM is an effective tool for mathematical modeling and factor analysis of the dyes adsorption process.

\section{Acknowledgement}

The authors grateful from the Iranian National Sciences Foundation and Research Council of the University of Yasouj for their financial support.

\section{References}

[1] S. An, X. Liu, L. Yang, L. Zhang, Chem. Eng. Res. Design, 94 (2015) 726-735.

[2] M.D. Pavlović, A.V. Buntić, K.R. Mihajlovski, S.S. Šiler-Marinković, D.G. Antonović, Ž. Radovanović, S.I. Dimitrijević-Branković, J. Taiwan Inst. Chem. Eng. 45 (2014) 1691-1699.

[3] M. Arulkumar, P. Sathishkumar, T. Palvannan, J. Hazard. Mater. 186 (2011) 827-834.

[4] A. Asfaram, M. Ghaedi, S. Hajati, M. Rezaeinejad, A. Goudarzi, M.K. Purkait, J. Taiwan Inst. Chem. Eng. 53 (2015) 80-91.

[5] A.A. El-Zahhar, N.S. Awwad, E.E. El-Katori, J. Mol. Liq. 199 (2014) 454-461.

[6] A. Asfaram, M. Ghaedi, S. Hajati, A. Goudarzi, RSC Adv. 5 (2015) 72300-72320.

[7] S. Hajati, M. Ghaedi, H. Mazaheri, Desalination Water Treat. DOI (2014) 1-15.

[8] L. Ai, C. Zhang, Z. Chen, J. Hazard. Mater. 192 (2011) 1515-1524.

[9] Y.S. Al-Degs, R. Abu-El-Halawa, S.S. Abu-Alrub, Chem. Eng. J. 191 (2012) 185-194. 
[10] S. Hajati, M. Ghaedi, F. Karimi, B. Barazesh, R. Sahraei, A. Daneshfar, J. Ind. Eng. Chem. 20 (2014) 564-571.

[11] C.-Z. Liang, S.-P. Sun, F.-Y. Li, Y.-K. Ong, T.-S. Chung, J. Membr. Sci. 469 (2014) 306-315.

[12] F.S. Kegel, B.M. Rietman, A.R. Verliefde, Water Sci. Technol. J. Int. Associat. Water Poll. Res. 61 (2010) 2603-2610.

[13] X. Chen, F. Zhang, Q. Wang, X. Han, X. Li, J. Liu, H. Lin, F. Qu, Dalton Trans. 44 (2015) 3034-3042.

[14] J. Qi, X. Li, H. Zheng, P. Li, H. Wang, J. Hazard. Mater. 293 (2015) 105-111.

[15] X. Guo, Y. Cai, Z. Wei, H. Hou, X. Yang, Z. Wang, Water Sci. Technol. J. Int. Associat. Water Poll. Res. 67 (2013) 1880-1885.

[16] M. Ghaedi, S. Hajati, B. Barazesh, F. Karimi, G. Ghezelbash, J. Ind. Eng. Chem. 19 (2013) 227-233.

[17] A. Asfaram, M. Ghaedi, G.R. Ghezelbash, E.A. Dil, I. Tyagi, S. Agarwal, V.K. Gupta, J. Mol. Liq. 214 (2016) 249-258.

[18] S. Hajati, M. Ghaedi, S. Yaghoubi, J. Ind. Eng. Chem. 21 (2015) 760-767.

[19] M. Ghaedi, H. Mazaheri, S. Khodadoust, S. Hajati, M.K. Purkait, Spectrochim. acta. Part A, 135 (2015) 479-490.

[20] M. Ghaedi, E. Alam barakat, A. Asfaram, B. Mirtamizdoust, A.A. Bazrafshan, S. Hajati, RSC Adva. 5 (2015) 42376-42387.

[21] H. Mazaheri, M. Ghaedi, S. Hajati, K. Dashtian, M.K. Purkait, RSC Adv. 5 (2015) 83427-83435.

[22] A. Asfaram, M. Ghaedi, A. Goudarzi, M. Rajabi, Dalton Trans. 44 (2015) 14707-14723.

[23] M. Soylak, I. Elci, M. Dogan, Asian J. Chem. 13 (2001) 1097-1100. 
[24] M. Ghaedi, S. Khodadoust, H. Sadeghi, M.A. Khodadoust, R. Armand, A. Fatehi, Spectrochim. acta. Part A, 136 (2015) 1069-1075.

[25] F. Nasiri Azad, M. Ghaedi, K. Dashtian, S. Hajati, A. Goudarzi, M. Jamshidi, New J. Chem. 39 (2015) 7998-8005.

[26] M. Tuzen, A. Sari, D. Mendil, M. Soylak, J. Hazard. Mater. 169 (2009) 263-270.

[27] M. Soylak, Fresenius Environmental Bulletin, 7 (1998) 383-387.

[28] A.R. Bagheri, M. Ghaedi, S. Hajati, A.M. Ghaedi, A. Goudarzi, A. Asfaram, RSC Adv. 5 (2015) 59335-59343.

[29] M. Ghaedi, S. Hajati, M. Zaree, Y. Shajaripour, A. Asfaram, M.K. Purkait, Adv. Powder Technol. 26 (2015) 1087-1093.

[30] A.A. Bazrafshan, S. Hajati, M. Ghaedi, RSC Adv. 5 (2015) 79119-79128.

[31] M. Ghaedi, M. Pakniat, Z. Mahmoudi, S. Hajati, R. Sahraei, A. Daneshfar, Spectrochim. Acta Part A, 123 (2014) 402-409.

[32] A. Asfaram, M. Ghaedi, S. Agarwal, I. Tyagi, V. Kumar Gupta, RSC Adv. 5 (2015) 18438-18450.

[33] M. Roosta, M. Ghaedi, A. Asfaram, RSC Adv. 5 (2015) 57021-57029.

[34] M. Ghaedi, A.M. Ghaedi, M. Hossainpour, A. Ansari, M.H. Habibi, A.R. Asghari, J. Ind. Eng. Chem. 20 (2014) 1641-1649.

[35] F.N. Azad, M. Ghaedi, K. Dashtian, S. Hajati, V. Pezeshkpour, Ultrason. Sonochem. 31 (2016) 383393.

[36] P. Saharan, G.R. Chaudhary, S. Lata, S. Mehta, S. Mor, Ultrason. Sonochem. 22 (2015) 317-325. 
[37] M. Ghaedi, S. Hajjati, Z. Mahmudi, I. Tyagi, S. Agarwal, A. Maity, V. Gupta, Chem. Eng. J. 268 (2015) 28-37.

[38] M. Roosta, M. Ghaedi, A. Daneshfar, R. Sahraei, A. Asghari, Ultrason. Sonochem. 21 (2014) 242252.

[39] M. Ghaedi, H.Z. Khafri, A. Asfaram, A. Goudarzi, Spectrochim. Acta Part A, 152 (2016) 233-240.

[40] M. Ghaedi, Z. Rozkhoosh, A. Asfaram, B. Mirtamizdoust, Z. Mahmoudi, A.A. Bazrafshan, Spectrochim. Acta Part A, 138 (2015) 176-186.

[41] M. Ghaedi, S. Heidarpour, S. Nasiri Kokhdan, R. Sahraie, A. Daneshfar, B. Brazesh, Powder Technol. 228 (2012) 18-25.

[42] M. Dastkhoon, M. Ghaedi, A. Asfaram, A. Goudarzi, S.M. Langroodi, I. Tyagi, S. Agarwal, V.K. Gupta, Sep. Purif. Technol. 156 (2015) 780-788.

[43] S. Khodadoust, M. Ghaedi, R. Sahraei, A. Daneshfar, J. Ind. Eng. Chem. 20 (2014) 2663-2670.

[44] F.N. Azad, M. Ghaedi, A. Asfaram, A. Jamshidi, G. Hassani, A. Goudarzi, M.H.A. Azqhandi, A. Ghaedi, RSC Adv. 6 (2016) 19768-19779.

[45] H.I. Chieng, L.B. Lim, N. Priyantha, Environ. Technol. 36 (2015) 86-97.

[46] M.M. Lakouraj, R.-S. Norouzian, S. Balo, J. Chem. Eng. Data, 60 (2015) 2262-2272.

[47] Y.-S. Ho, G. McKay, Process Biochem. 34 (1999) 451-465.

[48] K. Amela, M.A. Hassen, D. Kerroum, Energy Procedia, 19 (2012) 286-295.

[49] G.L. Dotto, J.M. Santos, I.L. Rodrigues, R. Rosa, F.A. Pavan, E.C. Lima, J. Colloid. Interface Sci. 446 (2015) 133-140.

[50] X. Jin, B. Yu, Z. Chen, J.M. Arocena, R.W. Thring, J. Colloid. Interface Sci. 435 (2014) 15-20. 
[51] L. Sun, S. Wan, W. Luo, Bioresour. Technol. 140 (2013) 406-413.

[52] M. Ghaedi, A. Ansari, R. Sahraei, Spectrochim. Acta Part A, 114 (2013) 687-694.

[53] L. Ai, C. Zhang, F. Liao, Y. Wang, M. Li, L. Meng, J. Jiang, J. Hazard. Mater. 198 (2011) 282-290.

[54] M. Jamshidi, M. Ghaedi, K. Dashtian, A.M. Ghaedi, S. Hajati, A. Goudarzi, E. Alipanahpour, Spectrochim. Acta Part A, 153 (2016) 257-267.

[55] T.A. Khan, E.A. Khan, Appl. Clay Sci. 107 (2015) 70-77.

[56] J.-F. Gao, Q. Zhang, K. Su, J.-H. Wang, Bioresour. Technol. 101 (2010) 5793-5801.

[57] I.A. Tan, A.L. Ahmad, B.H. Hameed, J. Hazard. Mater. 154 (2008) 337-346.

[58] S. Arabzadeh, M. Ghaedi, A. Ansari, F. Taghizadeh, M. Rajabi, Hum. Exp. Toxicol. 34 (2015) 153169.

[59] E.A. Dil, M. Ghaedi, A.M. Ghaedi, A. Asfaram, A. Goudarzi, S. Hajati, M. Soylak, S. Agarwal, V.K. Gupta, J. Ind. Eng. Chem. 34 (2016) 186-197.

[60] M. Ghaedi, A.M. Ghaedi, E. Negintaji, A. Ansari, A. Vafaei, M. Rajabi, J. Ind. Eng. Chem. 20 (2014) 1793-1803.

[61] S.M.A. El-Gamal, M.S. Amin, M.A. Ahmed, J. Environ. Chem. Eng. 3 (2015) 1702-1712.

[62] A. Mohammadzadeh, M. Ramezani, A.M. Ghaedi, J. Taiwan Inst. Chem. Eng. 59 (2016) 275-284.

[63] S. Dhananasekaran, R. Palanivel, S. Pappu, J. Adv. Res. 7 (2016) 113-124.

[64] S. Haider, N. Bukhari, S.Y. Park, Y. Iqbal, W.A. Al-Masry, Chem. Eng. Res. Design, 89 (2011) 2328. 
[65] L. You, Z. Wu, T. Kim, K. Lee, J. Colloid. Interface Sci. 300 (2006) 526-535.

[66] H. Chen, J. Zhao, A. Zhong, Y. Jin, Chem. Eng. J. 174 (2011) 143-150.

[67] A. Asfaram, M. Ghaedi, S. Hajati, A. Goudarzi, A.A. Bazrafshan, Spectrochim. Acta Part A, 145 (2015) 203-212. 
a)
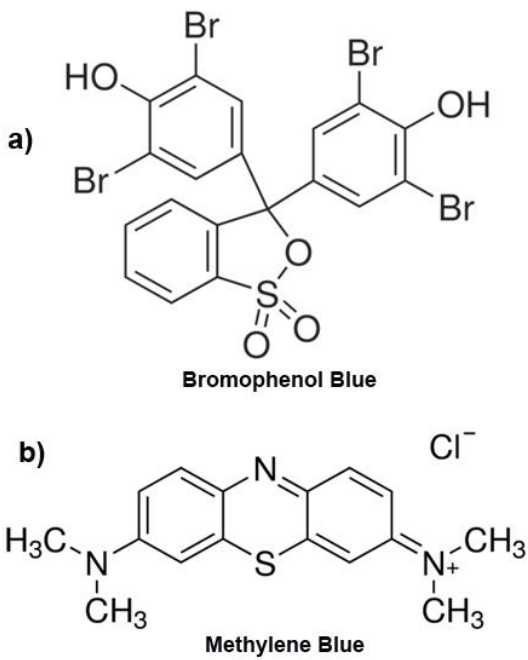

Fig. 1. Molecular structure of (a) bromophenol blue; (b) and methylene blue. 

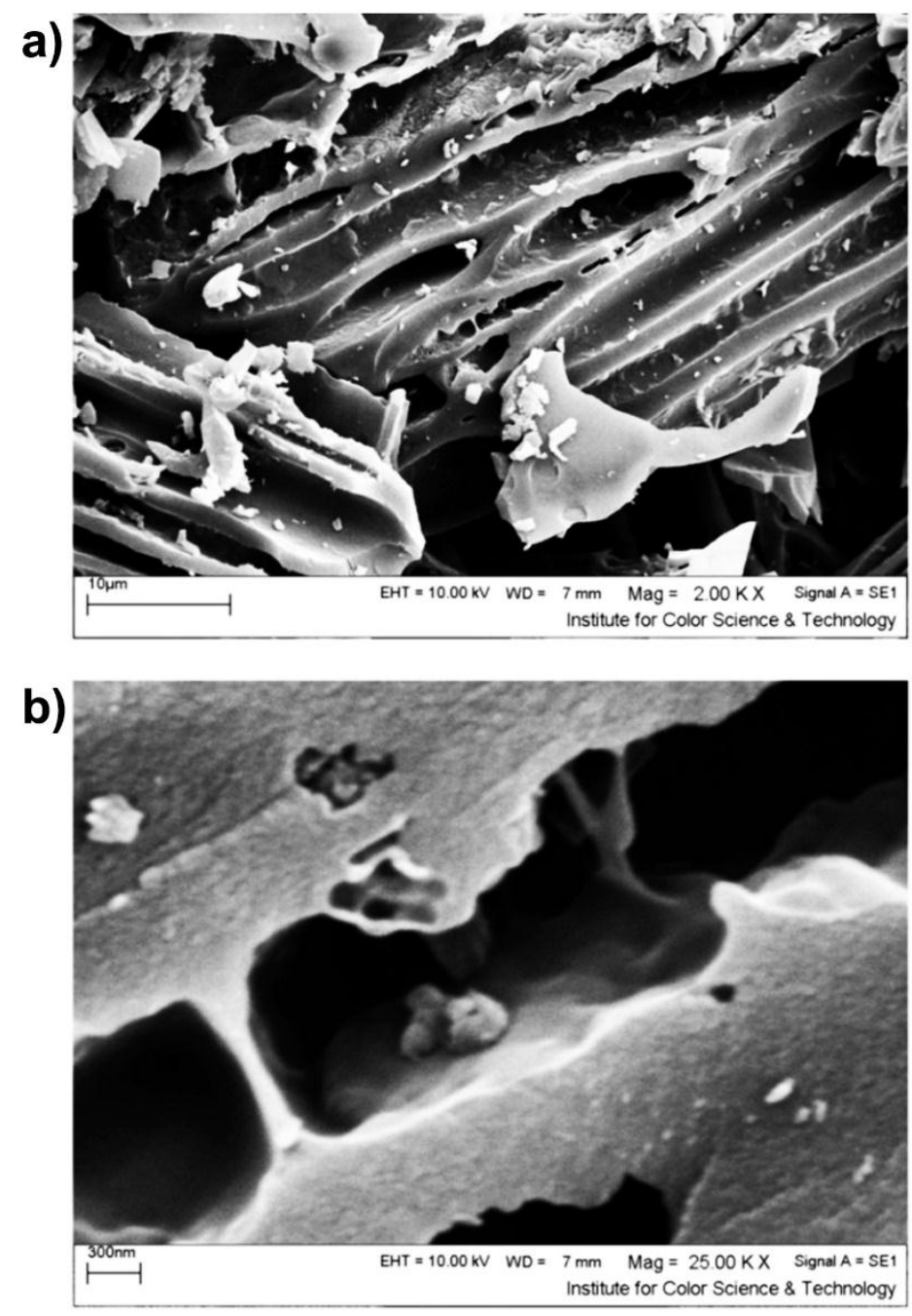

c)

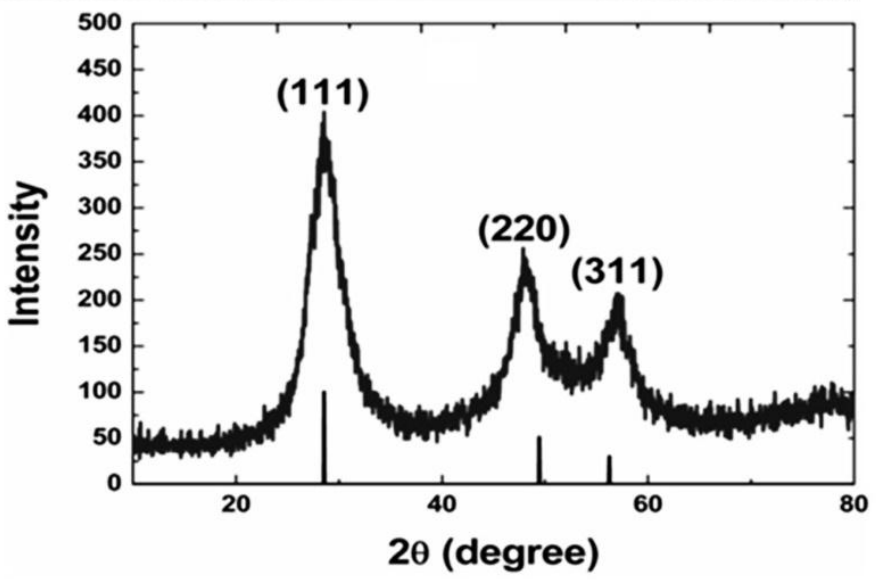

Fig. 2. (a, b) SEM images of CuS-NPs-AC at different magnifications and (c) XRD pattern and of CuSNP-AC. 


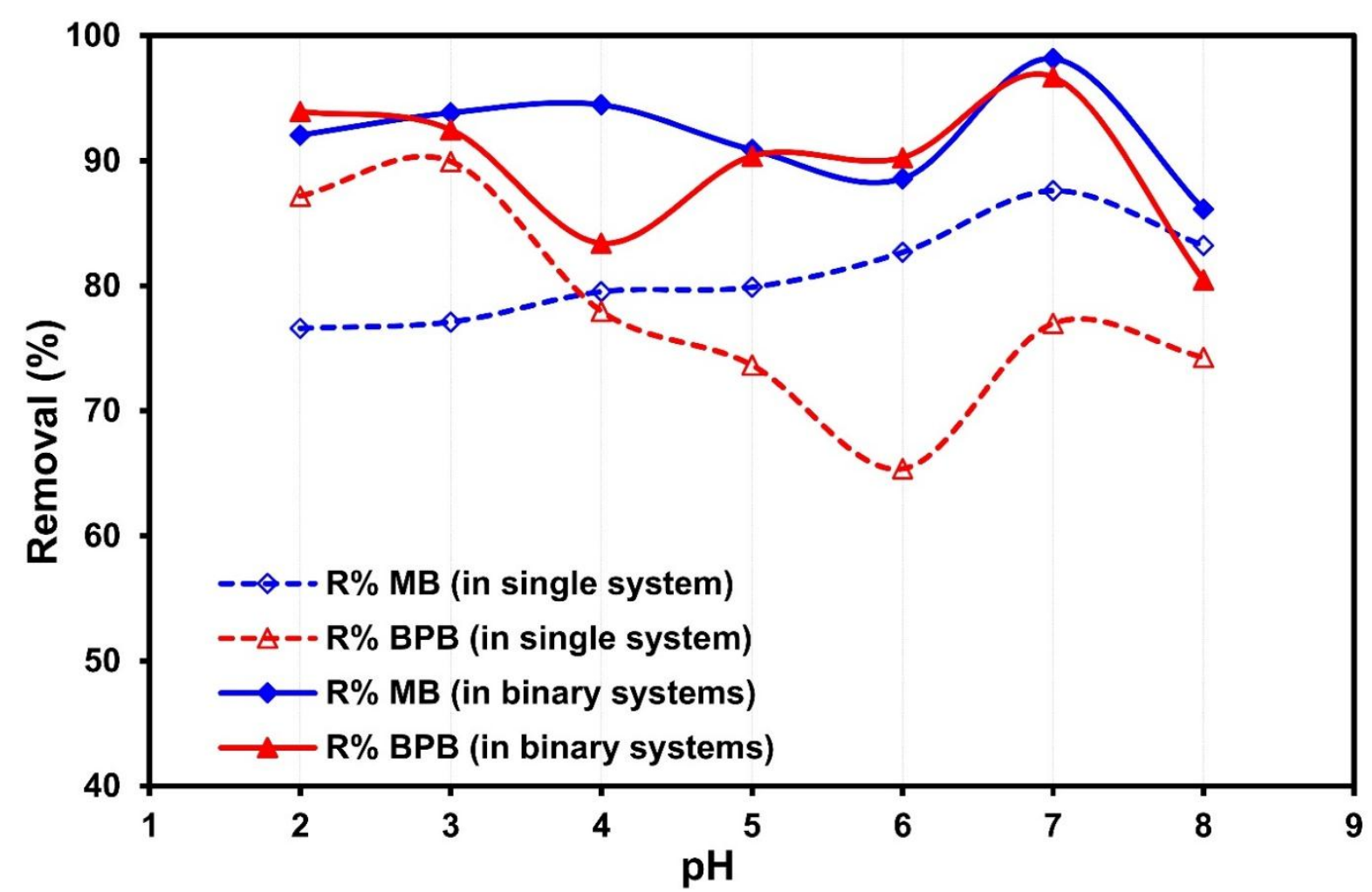

Fig 3. Effect of solution $\mathrm{pH}$ on the adsorption of dyes in single and binary systems onto CuS-NP-AC. (adsorbent amount: $0.005 \mathrm{~g}, \mathrm{~V}: 50 \mathrm{~mL}, \mathrm{~T}: 25^{\circ} \mathrm{C}$, initial concentration: $10 \mathrm{mg} \mathrm{L}^{-1}$ for each dye and $10 \mathrm{~min}$ sonication). 

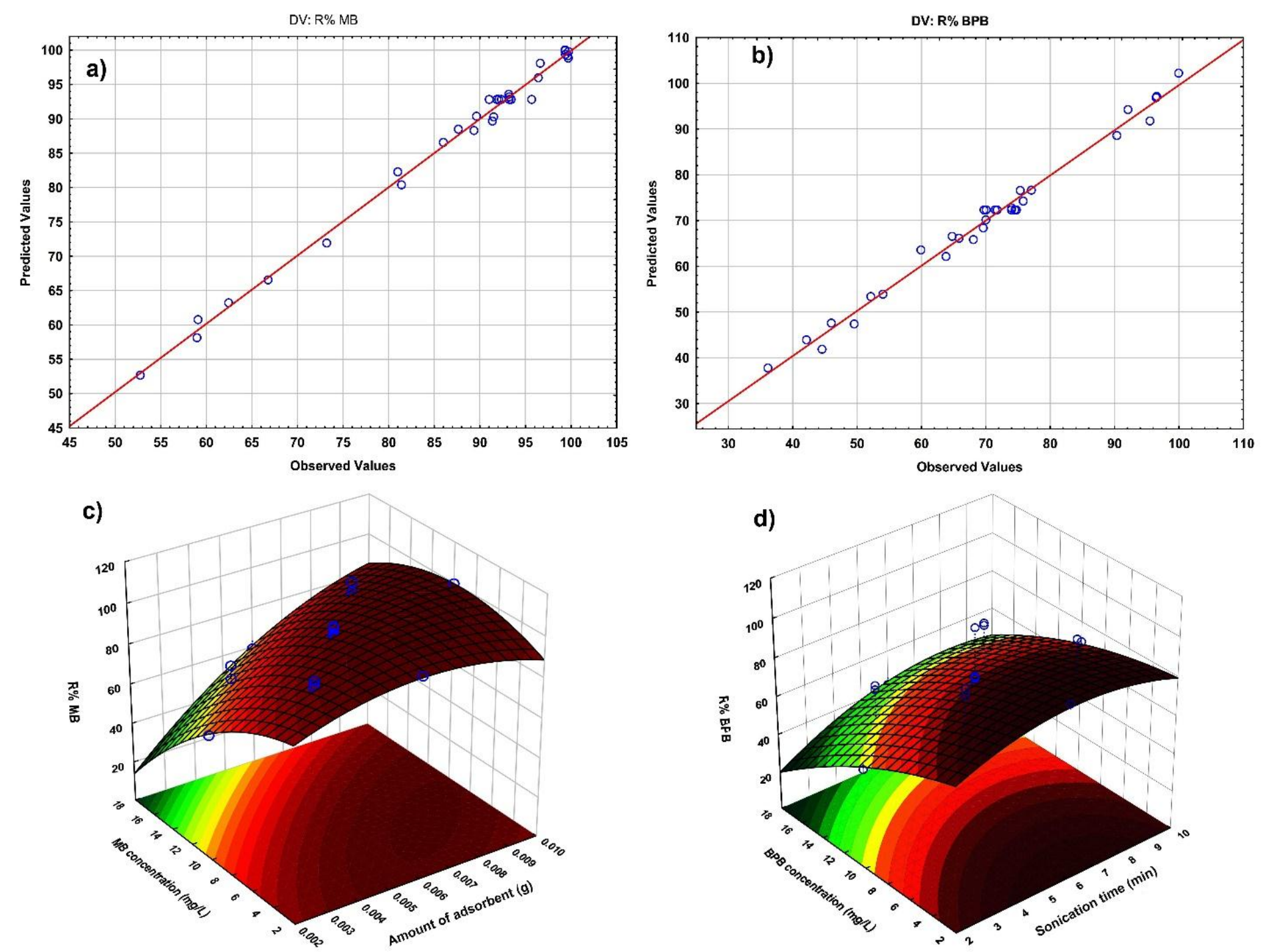

Fig. 4. Plot showing model predicted value versus observed value (a) MB and (b) BPB, (c) three dimensional response surfaces for the removal percentage of c) MB versus the amount of adsorbent and MB concentration and d) BPB versus the sonication time and BPB concentration. 
Amount of adsorbent

(g)
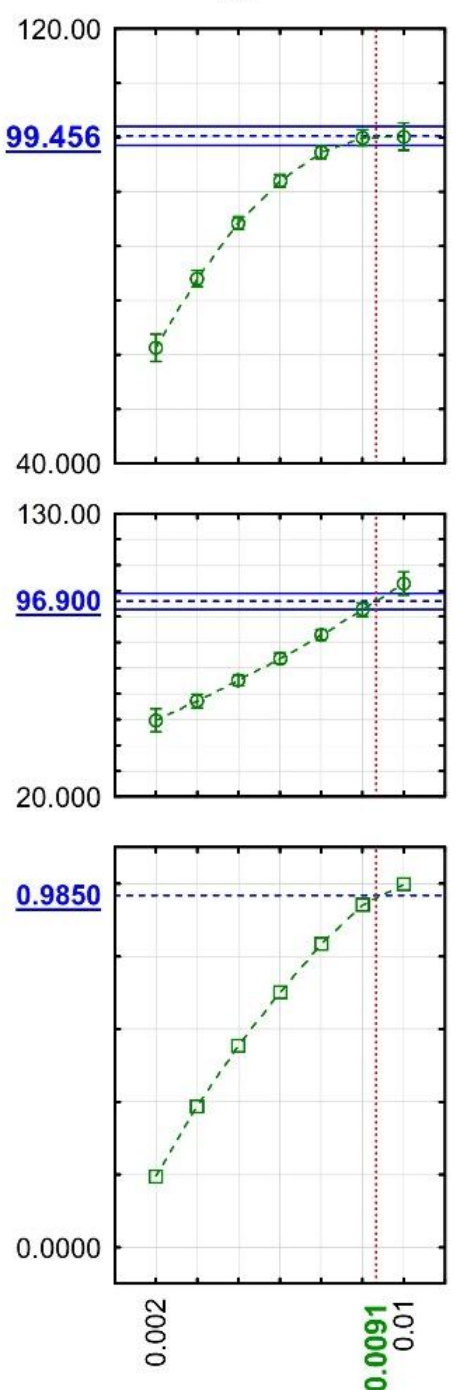

Sonication time

(min)
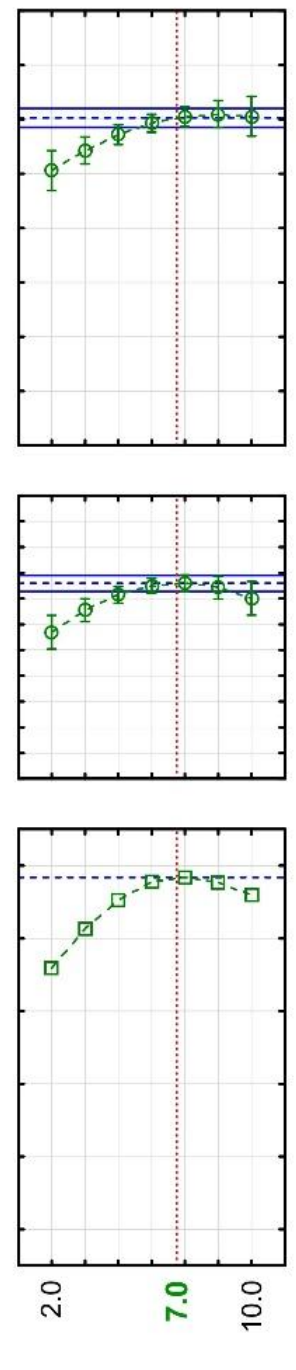

MB concentration

(mg/L)
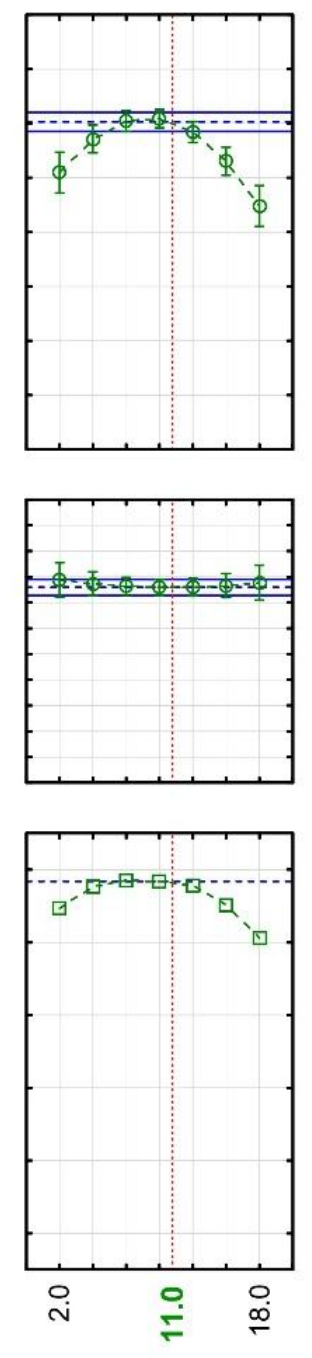

BPB concentration (mg/L)
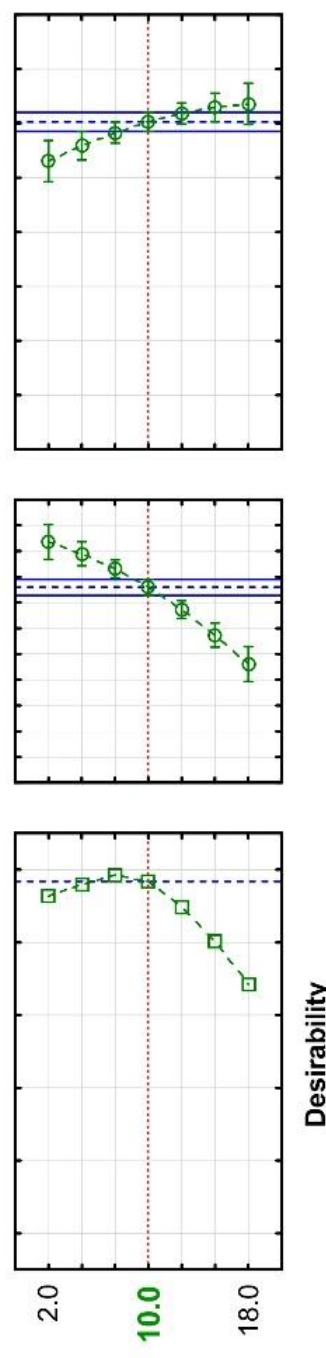

Desirability
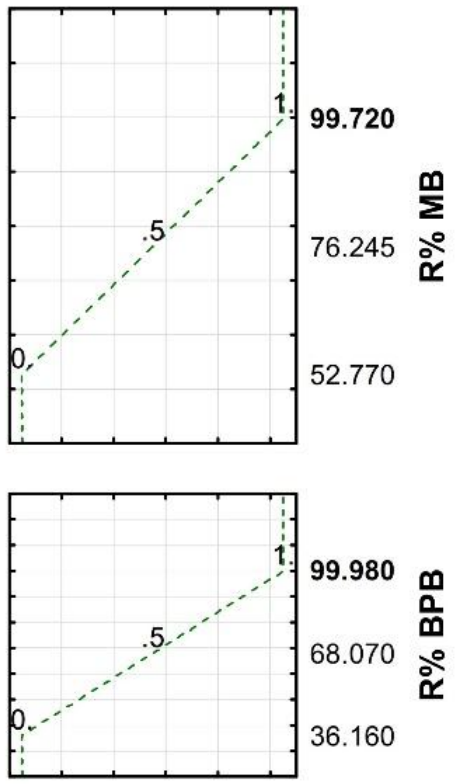

Fig.5. Optimization plot for the removal of MB and BPB by CuS-NP-AC. 
Table 1. The central composite design matrix of four test variables in coded and natural units along with corresponding experimental and predicted responses.

\begin{tabular}{|c|c|c|c|c|c|c|c|c|c|}
\hline \multirow{2}{*}{\multicolumn{3}{|c|}{ Variables }} & \multirow{2}{*}{ Code } & \multirow{2}{*}{ Unit } & \multicolumn{5}{|c|}{ Level of factors } \\
\hline & & & & & $-\alpha$ & Low $(-1)$ & Central (0) & High $(+1)$ & $+\alpha$ \\
\hline \multicolumn{3}{|c|}{ Amount of adsorbent } & $\mathrm{X}_{1}$ & $\mathrm{~g}$ & 0.002 & 0.004 & 0.006 & 0.008 & 0.010 \\
\hline \multicolumn{3}{|c|}{ sonication time } & $\mathrm{X}_{2}$ & $\min$ & 2 & 4 & 6 & 8 & 10 \\
\hline \multicolumn{3}{|c|}{ MB concentration } & $\mathrm{X}_{3}$ & $\mathrm{mg} \mathrm{L}^{-1}$ & 2 & 6 & 10 & 14 & 18 \\
\hline \multicolumn{3}{|c|}{ BPB concentration } & $\mathrm{X}_{4}$ & $\mathrm{mg} \mathrm{L}^{-1}$ & 2 & 6 & 10 & 14 & 18 \\
\hline \multicolumn{6}{|c|}{ Factors } & \multicolumn{2}{|c|}{$\mathrm{R} \% \mathrm{MB}$} & \multicolumn{2}{|c|}{ R\% BPB } \\
\hline Run & $\mathrm{X}_{1}$ & $\mathrm{X}_{2}$ & \multicolumn{2}{|l|}{$\mathrm{X}_{3}$} & $\mathrm{X}_{4}$ & Observed & Predicted & Observed & Predicted \\
\hline 1 & 0.004 & 4 & \multicolumn{2}{|l|}{6} & 6 & 91.38 & 89.65 & 63.80 & 62.16 \\
\hline 2 & 0.008 & 4 & \multicolumn{2}{|l|}{6} & 6 & 99.35 & 100.00 & 92.07 & 94.26 \\
\hline 3 & 0.004 & 8 & \multicolumn{2}{|l|}{6} & 6 & 93.15 & 93.57 & 64.74 & 66.56 \\
\hline 4 & 0.008 & 8 & \multicolumn{2}{|l|}{6} & 6 & 99.33 & 99.94 & 96.55 & 97.17 \\
\hline 5 & 0.004 & 4 & \multicolumn{2}{|l|}{14} & 6 & 52.77 & 52.66 & 59.89 & 63.54 \\
\hline 6 & 0.008 & 4 & 14 & & 6 & 81.41 & 80.41 & 95.50 & 91.79 \\
\hline 7 & 0.004 & 8 & 14 & & 6 & 66.79 & 66.55 & 69.98 & 70.13 \\
\hline 8 & 0.008 & 8 & 14 & & 6 & 91.50 & 90.30 & 96.45 & 96.90 \\
\hline 9 & 0.004 & 4 & 6 & & 14 & 85.97 & 86.58 & 36.16 & 37.77 \\
\hline 10 & 0.008 & 4 & 6 & & 14 & 99.37 & 99.37 & 68.09 & 65.84 \\
\hline 11 & 0.004 & 8 & 6 & & 14 & 89.62 & 90.38 & 46.00 & 47.62 \\
\hline 12 & 0.008 & 8 & 6 & & 14 & 99.67 & 99.17 & 75.79 & 74.20 \\
\hline 13 & 0.004 & 4 & 14 & & 14 & 58.99 & 58.14 & 44.56 & 41.85 \\
\hline 14 & 0.008 & 4 & 14 & & 14 & 89.34 & 88.32 & 65.83 & 66.07 \\
\hline 15 & 0.004 & 8 & 14 & & 14 & 73.20 & 71.92 & 54.03 & 53.90 \\
\hline 16 & 0.008 & 8 & 14 & & 14 & 96.60 & 98.09 & 77.08 & 76.63 \\
\hline 17 & 0.002 & 6 & 10 & & 10 & 62.45 & 63.23 & 49.56 & 47.37 \\
\hline 18 & 0.010 & 6 & 10 & & 10 & 99.72 & 99.77 & 99.98 & 102.21 \\
\hline 19 & 0.006 & 2 & 10 & & 10 & 80.98 & 82.27 & 52.12 & 53.41 \\
\hline 20 & 0.006 & 10 & 10 & & 10 & 96.42 & 95.96 & 69.63 & 68.37 \\
\hline 21 & 0.006 & 6 & 2 & & 10 & 99.68 & 98.83 & 73.98 & 72.77 \\
\hline 22 & 0.006 & 6 & 18 & & 10 & 59.08 & 60.76 & 75.34 & 76.58 \\
\hline 23 & 0.006 & 6 & 10 & & 2 & 87.64 & 88.50 & 90.35 & 88.57 \\
\hline 24 & 0.006 & 6 & 10 & & 18 & 93.24 & 93.21 & 42.10 & 43.92 \\
\hline 25 & 0.006 & 6 & 10 & & 10 & 95.68 & 92.81 & 73.98 & 72.31 \\
\hline 26 & 0.006 & 6 & 10 & & 10 & 91.01 & 92.81 & 70.05 & 72.31 \\
\hline 27 & 0.006 & 6 & 10 & & 10 & 92.35 & 92.81 & 74.76 & 72.31 \\
\hline 28 & 0.006 & 6 & 10 & & 10 & 93.24 & 92.81 & 71.75 & 72.31 \\
\hline 29 & 0.006 & 6 & 10 & & 10 & 92.07 & 92.81 & 69.70 & 72.31 \\
\hline 30 & 0.006 & 6 & 10 & & 10 & 93.45 & 92.81 & 74.51 & 72.31 \\
\hline 31 & 0.006 & 6 & 10 & & 10 & 91.87 & 92.81 & 71.43 & 72.31 \\
\hline
\end{tabular}


Table 2. Adequacy of model tested and analysis of variance for the experimental results of the CCD.

\begin{tabular}{|c|c|c|c|c|c|c|c|c|c|}
\hline Response & \multicolumn{5}{|c|}{ MB } & \multicolumn{4}{|c|}{ BPB } \\
\hline Source & $\mathrm{Df}^{\mathrm{b}}$ & $\mathrm{SS}^{\mathrm{a}}$ & $\mathrm{MS}^{\mathrm{c}}$ & F-value & P-value & $\mathrm{SS}^{\mathrm{a}}$ & $\mathrm{MS}^{\mathrm{c}}$ & F-value & P-value \\
\hline Model & 14 & 5472.622 & 390.902 & 185.121 & $<0.0001$ & 8266.690 & 590.478 & 87.510 & $<0.0001$ \\
\hline $\mathrm{X}_{1}$ & 1 & 2002.643 & 2002.643 & 948.400 & $<0.0001$ & 4511.111 & 4511.111 & 668.556 & $<0.0001$ \\
\hline$X_{2}$ & 1 & 281.287 & 281.287 & 133.210 & $<0.0001$ & 335.545 & 335.545 & 49.729 & $<0.0001$ \\
\hline$X_{3}$ & 1 & 2174.376 & 2174.376 & 1029.728 & $<0.0001$ & 21.738 & 21.738 & 3.222 & 0.0916 \\
\hline$X_{4}$ & 1 & 33.324 & 33.324 & 15.781 & 0.0011 & 2991.059 & 2991.059 & 443.281 & $<0.0001$ \\
\hline $\mathrm{X}_{1} \mathrm{X}_{2}$ & 1 & 16.023 & 16.023 & 7.588 & 0.0141 & 2.221 & 2.221 & 0.329 & 0.5742 \\
\hline $\mathrm{X}_{1} \mathrm{X}_{3}$ & 1 & 301.945 & 301.945 & 142.993 & $<0.0001$ & 14.821 & 14.821 & 2.196 & 0.1578 \\
\hline $\mathrm{X}_{1} \mathrm{X}_{4}$ & 1 & 5.873 & 5.873 & 2.781 & 0.1148 & 16.243 & 16.243 & 2.407 & 0.1403 \\
\hline $\mathrm{X}_{2} \mathrm{X}_{3}$ & 1 & 99.415 & 99.415 & 47.081 & $<0.0001$ & 4.841 & 4.841 & 0.717 & 0.4095 \\
\hline $\mathrm{X}_{2} \mathrm{X}_{4}$ & 1 & 0.012 & 0.012 & 0.006 & 0.9402 & 29.700 & 29.700 & 4.402 & 0.0521 \\
\hline $\mathrm{X}_{3} \mathrm{X}_{4}$ & 1 & 73.279 & 73.279 & 34.703 & $<0.0001$ & 7.291 & 7.291 & 1.081 & 0.3140 \\
\hline $\mathrm{X}_{1}^{2}$ & 1 & 228.517 & 228.517 & 108.220 & $<0.0001$ & 10.947 & 10.947 & 1.622 & 0.2201 \\
\hline $\mathrm{X}_{2}^{2}$ & 1 & 24.369 & 24.369 & 11.540 & 0.0037 & 233.088 & 233.088 & 34.544 & $<0.0001$ \\
\hline $\mathrm{X}_{3}{ }^{2}$ & 1 & 302.626 & 302.626 & 143.316 & $<0.0001$ & 9.996 & 9.996 & 1.481 & 0.2412 \\
\hline$X_{4}^{2}$ & 1 & 6.814 & 6.814 & 3.227 & 0.0913 & 65.817 & 65.817 & 9.754 & 0.0066 \\
\hline Residual & 16 & 33.786 & 2.112 & & & 107.961 & 6.748 & & \\
\hline Lack of Fit & 10 & 20.071 & 2.007 & 0.878 & 0.5929 & 81.322 & 8.132 & 1.832 & 0.2369 \\
\hline Pure Error & 6 & 13.714 & 2.286 & & & 26.639 & 4.440 & & \\
\hline Cor Total & 30 & 5506.407 & & & & 8374.650 & & & \\
\hline \multicolumn{10}{|c|}{ Model summary statistics } \\
\hline Response & & $\mathrm{R}^{2}$ & djusted & & Predicted & $\mathrm{SD}$ & Mean & $\mathrm{CV} \%$ & $\mathrm{AP}$ \\
\hline $\mathrm{R} \% \mathrm{MB}$ & & 994 & .989 & & 0.976 & 1.453 & 87.010 & 1.670 & 46.850 \\
\hline $\mathrm{R} \% \mathrm{BPB}$ & & 987 & .976 & & 0.938 & 2.598 & 69.860 & 3.718 & 35.660 \\
\hline
\end{tabular}

${ }^{\mathrm{a}}$ Sequential sums of squares

${ }^{b}$ Degrees of freedom

${ }^{\mathrm{c}}$ Mean sums of squares 
Table 3. Kinetic parameters of BPB and MB removal in binary solutions (adsorbent amount of $0.0041-0.0091 \mathrm{~g}$, sonication time of $7 \mathrm{~min}$, $11 \mathrm{mg} \mathrm{L} \mathrm{L}^{-1}$ of MB, $10 \mathrm{mg} \mathrm{L}^{-1}$ of BPB and $\mathrm{pH}$ 7.0)

\begin{tabular}{|c|c|c|c|c|c|c|c|}
\hline \multirow{2}{*}{ Models } & \multirow{2}{*}{ Parameters } & \multicolumn{3}{|c|}{ BPB } & \multicolumn{3}{|c|}{ MB } \\
\hline & & $0.0041(\mathrm{~g})$ & $0.0091(\mathrm{~g})$ & $0.0140(\mathrm{~g})$ & $0.0041(\mathrm{~g})$ & $0.0091(\mathrm{~g})$ & $0.0140(\mathrm{~g})$ \\
\hline \multirow{3}{*}{ First order kinetic model } & $\mathrm{K}_{1}\left(\min ^{-1}\right)$ & 0.244 & 0.438 & 0.559 & 0.465 & 0.609 & 0.627 \\
\hline & $\mathrm{q}_{\mathrm{e}(\mathrm{cal})}\left(\mathrm{mg} \mathrm{g}^{-1}\right)$ & 53.44 & 52.119 & 32.122 & 139.540 & 30.775 & 14.090 \\
\hline & $\mathrm{R}^{2}$ & 0.924 & 0.920 & 0.905 & 0.832 & 0.966 & 0.971 \\
\hline \multirow{4}{*}{ Second order kinetic model } & $\mathrm{K}_{2}\left(\mathrm{~g} \mathrm{mg}^{-1} \mathrm{~min}^{-1}\right)$ & 0.005 & 0.025 & 0.032 & 0.005 & 0.041 & 0.079 \\
\hline & $\mathrm{q}_{\mathrm{e}(\mathrm{cal})}\left(\mathrm{mg} \mathrm{g}^{-1}\right)$ & 80.000 & 57.471 & 37.879 & 129.870 & 62.500 & 40.486 \\
\hline & $\mathrm{R}^{2}$ & 0.990 & 0.991 & 0.997 & 0.992 & 0.999 & 0.999 \\
\hline & $\mathrm{h}$ & 30.864 & 83.895 & 46.083 & 86.950 & 161.290 & 129.870 \\
\hline \multirow[t]{3}{*}{ Intraparticle diffusion } & $\begin{array}{l}\mathrm{K}_{\text {dif }} \\
\left(\mathrm{mg} \cdot \mathrm{g}^{-1} \cdot \mathrm{min}^{-1 / 2}\right)\end{array}$ & 19.091 & 10.619 & 5.457 & 24.490 & 6.580 & 3.589 \\
\hline & $\mathrm{C}\left(\mathrm{mg} \mathrm{g}^{-1}\right)$ & 7.602 & 18.758 & 19.200 & 40.571 & 41.960 & 29.300 \\
\hline & $\mathrm{R}^{2}$ & 0.940 & 0.985 & 0.921 & 0.978 & 0.792 & 0.803 \\
\hline \multirow[t]{2}{*}{ Elovich } & $\beta\left(\mathrm{g} \mathrm{mg}^{-1}\right)$ & 0.054 & 0.100 & 0.192 & 0.043 & 0.150 & 0.279 \\
\hline & $\mathrm{R}^{2}$ & 0.979 & 0.966 & 0.935 & 0.981 & 0.903 & 0.888 \\
\hline Experimental date & $\mathrm{q}_{\mathrm{e}(\exp )}\left(\mathrm{mg} \mathrm{g}^{-1}\right)$ & 72.120 & 51.100 & 35.107 & 115.854 & 60.055 & 39.046 \\
\hline
\end{tabular}


Table 4. Comparison of the coefficient of isotherm parameter for MB and BPB adsorption on CuSNPs-AC using different concentration in single and binary systems (adsorbent amount of $0.0091 \mathrm{~g}$, sonication time of $7 \mathrm{~min}$ and $\mathrm{pH} 7.0$ ).

\begin{tabular}{|c|c|c|c|c|c|}
\hline \multirow[t]{2}{*}{ Isotherm } & \multirow{2}{*}{ Parameters } & \multicolumn{4}{|c|}{ dyes } \\
\hline & & MB & MB (mix) & BPB & BPB (mix) \\
\hline \multirow{5}{*}{ Langmuir } & $\mathrm{q}_{\mathrm{m}}\left(\mathrm{mg} \mathrm{g}^{-1}\right)$ & 208.330 & 166.670 & 106.380 & 91.740 \\
\hline & $\mathrm{K}_{\mathrm{L}}\left(\mathrm{L} \mathrm{mg}^{-1}\right)$ & 6.000 & 3.428 & 4.476 & 2.370 \\
\hline & $\mathrm{R}_{\mathrm{L}}$ & $0.006-0.070$ & $0.010-0.116$ & $0.007-0.101$ & $0.017-0.174$ \\
\hline & $\mathrm{R}^{2}$ & 0.995 & 0.997 & 0.994 & 0.996 \\
\hline & $p_{i}$ & \multicolumn{2}{|c|}{1.250} & \multicolumn{2}{|c|}{1.160} \\
\hline \multirow{3}{*}{ Freundlich } & $1 / n$ & 0.431 & 0.600 & 0.352 & 0.262 \\
\hline & $\mathrm{K}_{\mathrm{F}}\left(\mathrm{L} \mathrm{mg}^{-1}\right)$ & 138.134 & 180.717 & 65.887 & 51.665 \\
\hline & $\mathrm{R}^{2}$ & 0.659 & 0.941 & 0.744 & 0.938 \\
\hline \multirow{3}{*}{ Temkin } & B & 30.089 & 38.808 & 17.578 & 10.638 \\
\hline & $\mathrm{K}_{\mathrm{T}}\left(\mathrm{L} \mathrm{mg}^{-1}\right)$ & 101.659 & 52.797 & 90.284 & 322.737 \\
\hline & $\mathrm{R}^{2}$ & 0.876 & 0.984 & 0.813 & 0.988 \\
\hline \multirow{4}{*}{$\begin{array}{l}\text { Dubinin and } \\
\text { Radushkevich }\end{array}$} & $\mathrm{Q}_{\mathrm{s}}\left(\mathrm{mg} \mathrm{g}^{-1}\right)$ & 195.156 & 159.493 & 91.387 & 75.001 \\
\hline & $\beta \times 10^{-8}\left(\mathrm{~mol}^{2} \mathrm{~kJ}^{-2}\right)$ & 3.250 & 2.950 & 2.103 & 1.001 \\
\hline & $\mathrm{E}\left(\mathrm{kJ} \mathrm{mol}^{-1}\right)$ & 3.934 & 4.714 & 4.876 & 7.068 \\
\hline & $\mathrm{R}^{2}$ & 0.924 & 0.992 & 0.705 & 0.950 \\
\hline
\end{tabular}


Table. 5. Comparison for the removal of dyes by different methods and adsorbents.

\begin{tabular}{|c|c|c|c|}
\hline Adsorbent & Dye & adsorption capacity $\left(\mathrm{mg} \mathrm{g}^{-1}\right)$ & Ref. \\
\hline Activated carbon obtained from Astragalus bisulcatus tree & & 51.21 & [60] \\
\hline Sorel's cement nanoparticles & & 4.88 & [61] \\
\hline $\mathrm{Fe}_{2} \mathrm{O}_{3}-\mathrm{ZnO}-\mathrm{ZnFe}_{2} \mathrm{O}_{4} /$ carbon nanocomposite & & 90.91 & [62] \\
\hline$\alpha$-chitin nanoparticles & & 22.720 & [63] \\
\hline Polymer-clay composite & & 10.78 & [5] \\
\hline Thermally modified granular charcoal & & 101.62 & [64] \\
\hline Mesoporous hybrid gel derived from tetraethoxysilane and bis(trimethoxysilyl)hexane & & 27.60 & [65] \\
\hline Cupper sulfide nanoparticle loaded on activated carbon & BPB & 106.38 & This work \\
\hline Ag nanoparticles loaded on activated carbon & & 71.43 & [41] \\
\hline Graphene nanosheet/magnetite $\left(\mathrm{Fe}_{3} \mathrm{O}_{4}\right)$ composite & & 43.83 & [8] \\
\hline Magnetite loaded multi-wall carbon nanotube & & 48.06 & [53] \\
\hline Copper oxide nanoparticle loaded on activated carbon & & 10.55 & [34] \\
\hline Natural palygorskite & & 48.39 & [66] \\
\hline Palladium nanoparticles loaded on activated carbon & & 75.40 & [41] \\
\hline Gold nanoparticles loaded on activated carbon & & 104.00 & [38] \\
\hline $\mathrm{ZnO}$ nanorod-loaded activated carbon & & 89.29 & [59] \\
\hline copper-doped zinc sulfide nanoparticles loaded on activated carbon & & 123.46 & [67] \\
\hline Cupper sulfide nanoparticle loaded on activated carbon & MB & 208.33 & This work \\
\hline
\end{tabular}




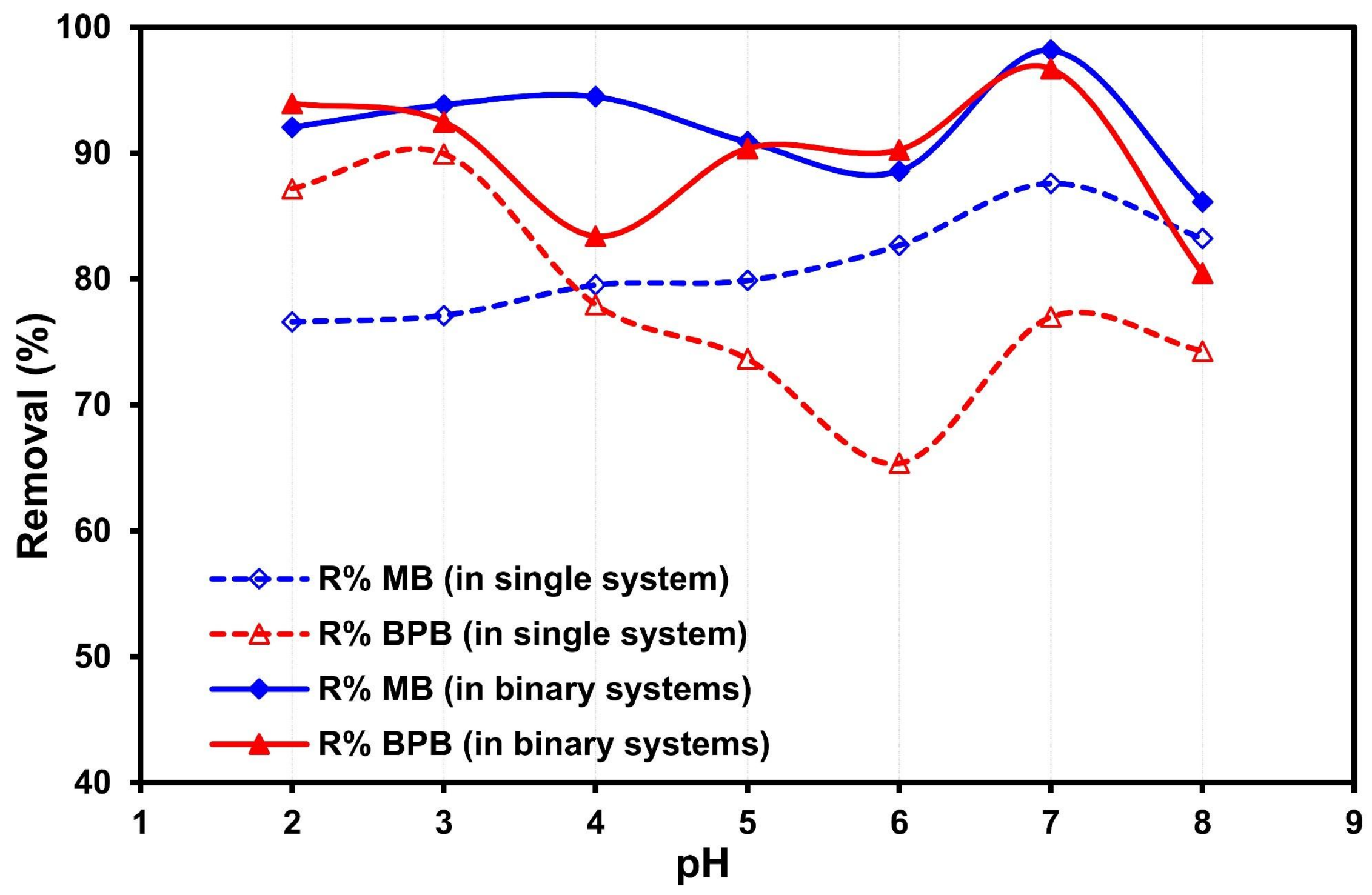

